\title{
Un acercamiento a la lírica de Helena Ospina en Sonata de otoño: Canción consumada
}

Conny Palacios

Academia Nicaragüense de la Lengua

Anderson University

E.E.U.U.

\section{Resumen}

Un acercamiento a la lírica de Helena Ospina es un título general, pero muy ambicioso, pues quiero darme a la tarea de un análisis literario de la poesía mística de la autora. Y, claro está, es un trabajo que me he asignado a mí misma por etapas. En esta ocasión me refiero específicamente al poemario Sonata de otoño. Canción consumada (1995). Y en este estudio indago sobre el proceso místico que se percibe en él, pero también hago referencia al uso simbólico del número tres, así como también destaco otros símbolos que considero esenciales en su lírica y que están presentes en esta obra.

Palabras claves: Helena Ospina, poesía mística, Sonata de otoño-Canción consumada, el proceso místico, simbología

\begin{abstract}
An approach to Helena Ospina`s lyric is a general and ambitious title, because I want to analyze the mystical poetry of the author. It is a task that I have assigned myself in stages. On this occasion I will refer specifically to Autumn Sonata. Consummated song (1995). In this paper I will study the mystical process involved and make reference to the symbolic use of the number three, as well as other symbols which I consider essential in her lyrics and that are present in this work.
\end{abstract}

Keywords: Helena Ospina, mystical poetry, Autumn Sonata-Consummated Song, the mystical process, symbology 


\section{Introducción}

Dámaso Alonso ha afirmado que: "El lector es el artista donde se completa la relación poética" (201), pero también ha dicho que: "El crítico es el despertador de la sensibilidad de futuros gustadores." (204) Y es, precisamente, desde esta posición de crítica que me acerco a Sonata de Otoño, Canción consumada de Helena Ospina, publicada en 1995. Asediada por el título me di a la tarea de analizarla, e inmediatamente vino a mí la reminiscencia de otra Sonata de Otoño, la de Valle Inclán. Y me dije a mí misma, ¿qué similitud o qué diferencia hay entre ellas? Y he aquí que a medida en que comenzaba a leer, se fue contestando mi pregunta. Para mi sorpresa, su título Sonata de otoño, con visos de amor pagano -por así llamarlo- nos arroja en su contenido a los brazos del Amor Divino, cantando a plenitud por los místicos del Siglo de Oro: San Juan de la Cruz y Santa Teresa.

\section{Sonata de otoño}

Sonata de otoño tiene un Proemio que es una reflexión escrita por la autora y constituye una guía -a través de la cual- la poeta nos lleva de la mano en sus Canciones. Esta introducción me la salté a propósito y la leí hasta que ya había leído los poemas. No quería de ninguna manera entrar predispuesta; la poesía es un templo donde se comunican las almas y debemos entrar descalzos en su recinto. Sólo así se establece la comunicación entre ellas.

\section{Canción consumada}

El poemario se caracteriza por el aliento místico y está constituido por ocho
Canciones de Amor a lo divino. ${ }^{1}$ Y llama la atención en ella, el uso del número 8 , ya que: "Camerarius, en su edición de la Aritmética de Nicomachus, lo llama la Armonía Universal, porque la armonía musical varía proporcionalmente a este número." (El poder oculto 129) Pues bien, estas 8 Canciones van en orden ascendente hacia la Armonía Universal, consonancia que llega a su clímax cuando se da la unión del alma con Dios.

Según Helmut Hatzfeld, el misticismo es: "el conocimiento experimental de la presencia divina, en que el alma tiene, como una gran realidad, un sentimiento de contacto con Dios." (Estudios 15) Y si pensamos en el misticismo como un progreso espiritual, como un movimiento que va siempre en orden ascendente, encontramos tres etapas. Hatzfeld las visualiza como olas y dice: "las inferiores representan en todos los niveles fases pasivas-purgativas, y las más altas representan primero las etapas iluminativas y después las unitivas en el sentido propio de la palabra." (Estudios 17)

\section{Canción I}

La poesía como Don es uno de los temas de la lírica ospiniana y se observa en otro de sus poemarios, Splendor Formae. En la Canción I, constituida por 50 cantos, este tema toma cuerpo, y se hace objeto de esta Canción. Y -según nos explica Helena Ospina en su Proemio- "el alma toma conciencia del don, don inmerecido y se dispone al Amor, a querer cantar las magnalia de Dios." (33)

1 Expresión usada por Dámaso Alonso en su análisis de San Juan de la Cruz. 
El primer poema de esta sección -"Un día salí”- nos remite al origen por así decirlo de la poesía ospiniana. La poeta nos explica que este breve poema tiene una base real. ${ }^{2}$ La importancia de este canto estriba entonces en que aquí se inicia "la historia de su lucha, de los ascensos y descensos de su vuelo...de sus arrobamientos y quejas por la presencia y la ausencia del amado." (32) Cito a continuación el poema en su totalidad, ya que es la piedra angular de este poemario:

Un día salí llorando....

No sabía quién era ni para qué servía.

Y llegaste Tú, niño, con rosa roja y nota que decía: "Quiero recorrer contigo los senderos del Amor"...

Y desde ese día supe quién era

y para qué me querías. (74)

En "Diles que no estoy", la poeta se cierra al mundo y confiesa que llegó la hora del Amor y por eso está solo para Él: “¡Diles que no estoy!/ Que estoy solo para Ti, ¡Amor!" (75) En el siguiente poema "Y ahora corro", la autora se ve acuciada por ese Amor, y ante esa premura se pone de inmediato a cantarlo, pues no sabe si tendrá el tiempo para hacerlo. El poema se distingue por el uso de un léxico amatorio profano, donde la búsqueda del Amor es un acto de cacería: "¿Y ahora me das Amor!/ Y la caza de tu Amor me lleva tan alto/ que no sé si me darás vida para poder plasmar todo este Amor." (75)

2 Un día cuando sale de camino está llorando, se siente confundida porque no sabe el porqué de su vivir. Se le acerca un niño y le ofrece una rosa roja con una tarjeta pequeña. En la tarjeta se lee. "Quiero recorrer contigo los senderos del Amor." (34)
En "Me tienes así", la poeta nos muestra cómo su diario vivir se desliza entre dos polos: “¡En intimidad! Con la dulzura y querer voluntarioso/ de la pequeña de Lisieux...", pero "con el temple y querer enérgico de la grande de Ávila" (78) "Ne Timeas" marca el inicio del Nuevo Pentecostés de su alma, en otras palabras, su resurrección: "Quedé tumbada y supe - con certeza-/ que comenzaba - en ese preciso momento- un Nuevo Pentecostés para mi alma." (78)

Con un léxico de amor carnal, la autora afirma que está enamorada del Amor. La Canción se caracteriza por el estribillo: “¡Estoy enamorada del Amor!” Y la importancia de esto estriba en que el uso de este recurso nos da, además del tema del poema, uno de los temas principales del poemario en cuestión: ¡Estoy enamorada del Amor!/ No hay nada que hacer./ No tengo más remedio ni perdón.../ ¡Que estoy enamorada del Amor!" (80)

Si pensamos en el proceso místico como un proceso de tres etapas, el poema "Ya no tengo mis batallas" es clave pues nos da la etapa en la que el alma se encuentra; la poeta mística ha entrado aquí en su etapa iluminativa, que es la intermedia. Ospina confiesa que ya no tiene sus luchas en las dos potencias del alma, inteligencia y voluntad. Ella quiere quedar anclada para siempre en el corazón del Amado: "Ya no tengo mis batallas/ en la inteligencia ni en la voluntad./ Las llevo ya en el corazón/ y allí las quiero dejar." El canto termina con dos versos claves hermosísimos; "Amor, antiguo, primero y pleno,/ Amor de siempre y para siempre, ¡Amor!” (81) 
Con tres verbos de gradación ascendente -“esculpir, tallar y cincelar" - se inicia la composición "El taller del Alma". El uso de estos verbos nos trae un eco de uno de los santos hindúes de ascendencia universal de este siglo, Paramahansa Yogananda. También este Devoto de Dios ve el alma como un bloque informe, piedra oscura, que el Amado debe cincelar:

Esculpes, tallas, cincelas el bloque informe del alma, para dejar, en cada golpe, el sello de tu Amor. y cuando la duda asoma al corazón me recojo - en ese taller del almaa ofrendar mi bloque informe para buscar la caricia de tu cincel, ¡Amor! (83)

Toda esta Canción I es un aprestamiento del alma para cantar al Amor, idea ya expresada en otros poemas anteriores. La repetición de esta idea - la poesía como Don- en diferentes poemas valida el tema, a la vez que lo manifiesta en la composición titulada "En orden de batalla". De nuevo se observa aquí el uso de verbos ternarios en gradación ascendente: conocer, amar y servir. Verbos de los que se reviste en la batalla de cada día y que sintetizan la tarea de su vida:

Estoy con el ánimo atento, el alma templada,

las manos y la mente "en orden de batalla".

"Conocer, amar y servirte": tarea de mi vida.

Así se pasa mi día entero - carrera divina- queriendo

librar con Tu gracia

¡todas tus batallas de Amor! (84)
Una de las características de los poemarios de Helena Ospina es que siempre nos va dejando "migas de pan", por así decirlo, para no perdernos en la abundancia copiosa de sus poemarios. Por eso podemos hablar de "nexos temáticos" que surgen de aquí y allá, en un despliegue casi táctico, para aherrojarnos - a nosotros los lectores- en su cerrada trabazón de Amor. Y en este caso me refiero al poema "Me ronda mi muerte". En él expresa la idea -ya manifestada casi al comienzo de este análisis- de que tiene que darse prisa porque el tiempo de merecer se le acaba:

Me ronda ya mi muerte y por eso corro.

Me llega la noche.

Cortas se quedan las horas, que para alcanzar - a mi Solse me acaba, se me acaba ya, ¡el tiempo de merecer! (85)

El poema "Hogueras" nos trae una reminiscencia de Santa Teresa. Su tema ya fue manifestado con anterioridad en "Diles que no estoy". El poema nos habla de sus faenas diarias, trabajos enmarcados en un creciente recogimiento espiritual, ya que la autora se confiesa estar "sustraída en" el Amor y "sustraída por" el Amor: "Y así me tienes -bien metida- en la faena/ ordinaria y diaria luchando por hacer con perfección humana/ lo que me pides sustraída por Vos y en Vos/ -suspendida por Vos y en Vos-/ en tu dulce Corazón.” (88)

Esta Canción I termina con el poema "Me dejas sin habla" y es importante porque - a como dice la autora en su introducción- "Comienza un nuevo Amar donde sobran las palabras y basta sólo la mirada." (36) En 
otras palabras, los versos de este breve poema sirven de preámbulo a la Canción II que es una nueva manera de expresar el Amor:

Me dejas sin habla,

Con sólo la mirada.

Y tu habla - sin habla-

va quemando mi mirada

hasta dejar grabada Tu habla - sin

habla-

en la entraña de mi alma. (92)

\section{Canción II}

Los versos anteriores nos remiten a la Canción II, que se desborda en 31 poemas. Es un nuevo hablar desde la perspectiva de la purificación. De esta etapa, la autora nos dice que aquí el alma se da cuenta de que hay cosas que debe de purificar, y el Amor -entonces para ayudarle- se le esconde y la deja. Y por esa razón: "empieza ella, como la novia del Cantar de los Cantares, a llorar su desaparición. Comienza a entender que toda la vida, aquí en la tierra, es un esconderse de su Amado -de su Sol-, porque quiere que le busque más en la fe que en el sentido." (32) Dada la condición anterior, la poeta se queja y le expresa que esta clase de Amor: "Es un ver sin verte; / un tener, sin tenerte;/ un amar sin poseerte." (95)

Los protagonistas de esta segunda Canción -que es una hermosa batalla de Amor, según palabras de la autora- son El Bautista y Lucas. De ellos, Helena Ospina afirma - en su introducción- que "El Bautista es el que le enseña a clamar con ardor incesante. Y Lucas, el pintor, el médico de almas- es quien le lleva por caminos de infancia del Emanuel, envuelto en pañales, sosegado en regazo de Madre.” (37)
La búsqueda del Amor en la fe no es un camino fácil; el alma vive en perpetuo duelo y por eso le pide al Cordero aunque sea una mirada para descansar en ella su dolor y su Amor:

Si al menos... ¡una mirada!

como la que Jesús cruzó con María camino de la Cruz:

y vio María a su Jesús

y vio Jesús a su María, y descansaron en aquella mirada los dos

su dolor y su Amor. (97)

Si anteriormente la autora nos dice que el Amor que se sostiene en la fe es un ver sin ver al Amado, es un tener sin tenerlo $\mathrm{y}$ es un amar sin poseerlo, ahora nos dice que el dolor que experimenta es tan grande que se compara a lo ya expresado, que es un modo de purificación. Por lo tanto, inferimos que la búsqueda del Amor y su dolor de amor por la ausencia continua del Amado son sentimientos iguales: “¿A qué puedo comparar, ése, mi dolor/ sino a esa purificación que a todos pides/ -en tierra o purgatorio- de verte sin verte/ de tenerte sin tenerte, de amarte sin poseerte?" (98)

Pero, a pesar de lo anterior, el alma sólo quiere vivir de ese amor, porque está tan enamo-

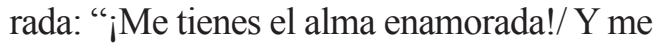
la tienes tan así de TI prendada/ que sólo de Amor quiere vivir mi nada." (100)

El vivir entre los polos del Amor y el Dolor -que ya sabemos son expresiones semejantes- rinde sus frutos, pues el alma encuentra en ellos su purificación, y así lo expresa en el breve poema titulado "Alas": "Me has quitado el lodo de las alas/ y en el 
vuelo su dulce peso me has hecho sentir./ Y el brillo a mis ojos y el brío a mi fuego/ has purificado." (102)

\section{Canción III}

La Canción III es más breve que las otras y su contenido se distribuye en 17 poemas. Helena Ospina nos dice de ella que: "Esta Canción es la del alma enamorada. Canta que es la hora del Amor y advierte que quiere estar solo para su Amor; quiere estar, a solas, desgranando coloquios encendidos con su Amor." (39) En esta hora del Amor, el alma confiesa que su dolor de amor lo quiere llevar a cuestas como oro y como lo más precioso que puede ofrendar: "Quiero llevar a cuestas mi dolor como oro,/ como incienso, como mirra, como lo más precioso/ que Te puedo ofrendar." (107)

Si bien es cierto que el alma en esta Canción III se desliza como embriagada, también es cierto que no le impide llevar a cabo sus tareas de cada día. Se comprueba lo anterior en el poema "iQué falta me haces!". Los versos nos traen a la memoria a otra gran representante de la poesía mística, Santa Teresa, con su vida agitada, trabajando siempre por su Carmelo. De esta manera la autora parece decirnos que en estos tiempos modernos -donde la prisa ya es un lugar común- es posible llevar una vida dedicada a amar a Dios:

Y así paso cada día -bien metida en la faenacon la voluntad clavada y las sienes bien ceñidas, intelectualmente, en la tarea...
Pero... ¡se me escapan!, ¡se me escapan!, oh mi dulce Bien, balbuceos a mares que te dicen

¡qué falta me haces!, oh mi dulce Bien. (110)

El tema de la composición anterior se repite en el último canto de esta sección titulado "Me tienes el corazón de poeta", y es importante porque reafirma lo ya dicho y de esta manera se convierte en un postulado de vida para la autora. Vive metida en la faena con corazón de poeta, trocando canciones de amor humano en amor divino:

Me tienes el corazón de poeta con "canción de fondo" que me acompaña y no me deja con la mirada y el ánimo clavados en $\mathrm{Ti}$

mientras avanza el día...

y allí -bien metida en la faename tienes con corazón de poeta. (111)

\section{Canción IV}

La cuarta Canción, según Helena Ospina, es la canción donde: "el alma comienza a entender el amar que le pide Dios: es de Amor en Amor para consumar su oblación, porque el Amor no consiente ni permite que descanse el amor sino en el Amor." (40) Esta parte -en contraposición con la antecedente- se distribuye en 58 poemas, y ahora lo que importa es Amar, porque ya han cesado las inquietudes y las angustias. Es casi -por así decirlo- un himno de alegría. Y se comprueba lo anterior en el canto que abre esta parte y que se titula "Ya cesaron todas las inquietudes": 
Cesaron ya todas las inquietudes, preocupaciones, angustias y tensiones, viniendo a ser colmadas y calmadas por tu Amor.

Lo único que importa ahora es Amar...

Y así voy -bien metida en la faenacon una sola meta: ¡Amar! (114)

En el siguiente poema, la autora nos explica cómo es ese amor que le pide Dios. Y para nuestro asombro nos damos cuenta de que el amor de Dios es a las vez divino y humano, y como humano, celoso y apasionado. La poeta también nos deja entrever que nosotros -como criaturas que reflejamos lo divino-, al amar de la manera ya expresada, reflejamos la manera en que Dios nos ama. Véase la composición “¡Madre! Yo no sabía”:

¡Madre! Yo no sabía que Dios cuando ama,

ama así con amor divino y humano, apasionado,

tomando posesión celosa de quien ama.

¡Madre! Yo no sabía que no soy yo quien ama, sino Dios -en mí- quien así ama,

con amor divino y apasionado. (114)

Si la meta es Amar y el Amor pide siempre más amor, el alma enamorada entonces no quiere descansar; lo único que desea es avanzar de amor en amor hacia el Amado, hasta fundirse con Él: "Y así, ¡Amor!, de amor en amor, me vas matando/ y Te voy yo amando/ que no quiero ya parar ni que me dejes descansar,/ que -de amor en amor-quiero hacia Ti avanzar." (118)
La idea de que Dios es un mendigo de amor desde toda una eternidad ${ }^{3}$ se nos presenta en el poema "Con tan poco te contentas", y por esa razón ha querido nacer - según la poeta- para que su Amor resplandezca en nuestra nada. Compruébese en los versos que siguen: "Con tan poca cosa te contentas ¡Amor!/ y desde toda una eternidad mendigas nuestro amor/ que para rescatar esta nada has querido nacer/ para -en ellatu Amor hacer resplandecer." (119)

El siguiente poema "Que te arroben mis ojos" es importante en esta sección, porque la voz poética se desborda en versos apasionados, encendidos de amor; amor que pierde sus límites y se hace cuerpo físico y espiritual. Y la importancia precisamente está en eso, ya que se convierte en una muestra del tipo de amor-divino y humano a la vez- que caracteriza a esta cuarta Canción: "¡Que te arroben mis ojos!/ ¡Que te hurten mis labios!/ ¡Que te besen mis manos!/ Para borrarte la herida del desamor." (120)

Una de las características de este poemario, -y me atrevo a decir de la lírica en general de Ospina- es la reiteración de (asuntos líricos) temas, que se da en todas las Canciones. Esto sirve como hilo conductor que, a la vez que guía al lector, sirve de estructura a la Canción. El tema, amor divino, amor humano, -del cual ya hablamos en líneas precedentes se reitera en este canto titulado "De claridad en claridad", y la autora se refiere a él como "la gran verdad descubierta". Conocimiento que se vuelve "río de Amor", inundándole a él como "la gran

3 Idea ya expresada por el poeta más místico Rabindranath Tagore, y Parahamansa Yogananda en sus enseñanzas espirituales. 
verdad descubierta." Conocimiento que se vuelve "río de Amor", inundándole constantemente el alma, aunque esté bien dedicada al ejercicio de sus labores:

De claridad en claridad se avanza... Y la gran verdad descubierta se torna en manso y dulce "ritorne1lo" -río de Amorque acompaña al alma y no la deja aunque tenga la vida entera -bien empeñada y metida-

en la faena. (121)

Los lectores se preguntarán cómo el alma puede avanzar de amor en Amor, si estamos bien metidos en la faena; en otras palabras, si vivimos cercados por el constante bullicio del mundo en medio de nuestras actividades cotidianas. Pues bien, no desesperemos, hay una capacidad que debemos fortalecer, y esa es la admiración.

Teniéndola no menguará nuestro deseo de penetrar la trama amorosa de Dios: "La admiración es el núcleo del Amor... /y cesa el deseo de penetrar la urdimbre amorosa,/ encarnada de mi Dios." (123)

El desbordarse por parte de la autora en versos enamorados, apasionados $-\mathrm{y}$ muy a lo divino- no es un mero recurso literario; es un sentir continuo en el que el alma vive, y a través del cual experimenta el proceso de avance hacia su última meta, la unión con el Amado: "Déjame hablarte, a Ti de Ti./ Déjame que Te diga que me tienes embelesada, Tú de Ti./ Déjame que te hable cuán enamorada me tienes, Tú de Ti./ Déjame que Te atisbe $-y$ que por un instante Te mire-/ para que Te diga que me tienes loca de amor, Tú de Ti." (124)
Cada día es un acercarse en el amor hacia el Amor, y como humano y divino que es, es celoso y nos exige fidelidad a su luz: “ $¡ O$ Oh Amor!, ¡me clavas en cada imagen/ y me exiges con tal fuerza fidelidad a esa luz/ que si no corresponde mi alma a tal finura/ me dejas sin poder avanzar en ese día en tu Amor!" (126)

A lo largo de esta Canción IV, surgen encendidas cancioncillas amatorias como las precedentes que vienen a ser chispas de amor que van empedrando, tejiendo e iluminando el entramado de esta Canción. Algunos ejemplos de estos desbordamientos son: "Reverberación”, "Quiero como David danzar", "Dio come ti amo", "Solo quiero tenerte a ti, Amor", "A veces me tienes amándote", etc.

Al comenzar el análisis de esta cuarta Canción, dijimos que era como un himno de alegría, la alegría de estar enamorada del Amor. Y para terminar, vemos que en el último poema - "Vivir siempre así"- la asunción anterior se comprueba, pues el alma sigue expresando su deseo de vivir siempre enamorada, balbuceante y desbordada algunas veces, pero, más que todo, entretenida perpetuamente en el Amor: "Yo quiero ¡Amor! Vivir siempre así.../ Con el alma enamorada y que todo tenga para mí/ la importancia que tiene para el alma enamorada./Y que nunca más ¡Amor! Me vuelva/ la prisa o el sueño a aherrojar el alma..." (133)

\section{Canción V}

En la Canción V nos dice la autora: el alma se da cuenta de que muere cada vez más de Amor. Su vivir es un morir-vivo que 
no vivo-, ${ }^{4}$ porque es el amor el que empieza a vivir más y más en ella." (33) Esta sección -más breve que la anterior-consta de 32 poemas. La Canción se inicia con una pregunta que sirve de título, “¿Qué es la muerte, Amor?" Y en el poema mismo encontramos la respuesta: ¿qué más puede ser? Nos dice la poeta, si no esta Vida que llevándome de aquí y de allá me das: “¿Qué es la muerte ¡oh Amor!/ si no esta Vida que - de Ti- aquí ya me das?/ Que de muerte en muerte, mi vida entera llevas/ para darme Vida, en vida Tuya, joh Amor!" (136)

En el poema que sigue -"Este Amor"-, es un Amor avasallador que, como tal, "no se colma ni se calma no conoce saciedad." (136) Es además fuerte como la muerte, golpea y fustiga constantemente hasta que se le entregue todo el corazón. Compruébese lo anterior en la composición "Fuerte como la muerte es tu Amor, / golpea fuertemente mente y corazón, / sigue y hiere hasta que le entregues/ -sin concesiones¡todo el corazón! (137)

Ya he dicho que este tipo de Amor es exigente, pero creo que el adjetivo le va un poco pequeño, y se debería de catalogar como súper exigente, ya que no tolera ningún tipo de eclipse -en este contexto, la más ligera sombra de desamor-, y si llega a ocurrir, quema con más ardor hasta lograr desvanecer la mancha: "No concedes ni toleras ¡oh amor! Con más claridad $\mathrm{y}$ ardor / hasta que logremos quitar esta mancha nuestra a tu Sol." (137) Vivir en y por este Amor -concluye la poeta en el

4 El tema del "Vivo sin vivir en mí", utilizado por San Juan de la Cruz y Santa Teresa, proviene de una tradición cortesana. siguiente canto- es una lucha a muerte que no sabe de tregua y por eso es: "¡Bella! Como ejército en orden de batalla”. (138)

Cabe destacar que esta sección se vuelve más íntima en su tono, y la extensión de los poemas es más corta; observamos la multiplicación de composiciones de dos, tres y cuatro versos. Esto es un reflejo de la profundidad del "acaramelamiento" del alma, ya que a medida que el ama se va enamorando más, ya sólo anhela la posesión del Amado, y es por eso que toda esta sección puede considerarse como un largo quejido enamorado, donde el alma se va rindiendo a este amor y, por ende, las palabras van sobrando. Muestra de lo anterior es el brevísimo canto "Es un vivir": "Es un vivir éste sin vivir, mi frágil vivir, / atravesado por la fuerza de tu Amor." (140) $\mathrm{Y}$, de la misma naturaleza, los siguientes: "Que sin Ti", "Tu dulce lagar", "Tu aljaba", "Hondonadas", etc.

A medida que nos acercamos al final de la Canción, asistimos al desconsuelo del alma que se acrecienta por la ausencia del Amado, y por lo tanto no encuentra alivio en "este destierro de Amor." El verbo morir -repetido muchas veces a lo largo de la Canción- se conjuga a plenitud en la penúltima composición, y claramente nos dice que muere -mejor dicho, nos grita- que muere de dolor de Amor: "Muero ¡Amor! de dolor de Amor. / Que no hay en esta tierra Consuelo, ¡Amor!/ Muero ¡Amor! de dolor de Amor.” (143)

\section{Canción VI}

En 22 poemas se nos presenta la sexta Canción y, según Helena Ospina, esta es la de 
La posesión. Aquí -continúa la autora- "el alma lo que ansía es la posesión del Amor. Se lo pide. Emplaza a quien ama y le dice: "Que ya he corrido tus lides ¡Amor!/ y en este destierro se siente baldío mi amor.../ Que ya he recorrido tus lides ¡Amor!/ y quiero al fin poseerte ¡Amor!” (146)

Pero el alma, aunque ya está transida de amor en este destierro, todavía tiene elementos de flaqueza, y eso acrecienta su dolor y por ende su desespero. Y es precisamente por esto que esta sección se caracteriza por un tono más fuerte, en el sentido de demanda, en contraste con la Canción V. Ejemplo de esta actitud son los siguientes cantos: "¿Qué cuesta? "Un Miserere", "Me tienes en un destierro", "¿Qué quieres que ansíe?" Este último, casi se podría decir, que tiene un tono de enojo: ¡Amor! ¿Qué quieres que ansíe? "¿Qué quieres que pida?/ Si sólo a Vos pido y ya nada más quiero ¡Amor! ¿Qué quieres que pida?/ Si solo a Vos pido y ya nada más quiero ¡Amor!/ ¿Qué quieres que pida? ¿Qué quieres que ansíe?/ Si ya nada me llena y sólo a Ti quiero ¡Amor!” (149)

El alma, no contenta con lo anterior, prosigue en su demanda y muestra su corazón clavado, casi exangüe en su dolor. Y por eso le urge al encuentro, y con no poca vehemencia le increpa: "¡Amor! A Ti ¿qué más da?: tenerme aquí o allá,..." (150) Termina esta Canción con un tono conciliador y le recuerda al Amado las tres Gracias que de Él recibió; en otras palabras, le recuerda que Él es el responsable de esta pena de Amor, y como tal tiene que curarla. Artificio retórico del alma en su desespero por la unión: "Cautivaste mi alma primero por la Belleza, / viniste luego a unirle tu Verdad, / impulsaste mi voluntad a tu Bien/y ahora estas tres Gracias no se separan de Ti jamás." (152)

\section{Canción VII}

El alma continúa en su búsqueda en la séptima Canción: La Glorificación. Esta Canción se caracteriza por un largo número de poemas, 89 en total; pero el discurrir del alma con el Amado se hace más suave; ha dejado atrás la angustia y la demanda. Ahora: "En esta Canción el alma sueña con la gloria que el Amor tiene reservada para los que luchan en esta hermosísima batalla de Amor." (53) Ya en esta etapa del proceso místico se observa una íntima comunión, donde la Palabra se hace vestidura del alma: "Cómo se modula y se moldea -como traje- en mi alma/ tu palabra joh Amor!/ Y cómo Te abrazan mi cabeza y mi alma/ ¡oh Palabra! ¡Oh amor! (157)

Uno de los temas de la lírica ospiniana es el del origen de la poesía que es divino, afirmación que se encuentra en Splendor Formae. Su dardo -que viene del Espírituse encarna en nosotros y regresa a Él. Por lo tanto, hacer poesía para la autora es una expresión de amor que vuelve a su origen, y cuando eso se da asistimos a la comunión del alma con su Creador. Y esto adquiere relevancia en esta Canción, porque la autora da gracias por la poesía, porque le sirve de pretexto para hablar del Amado. Y así

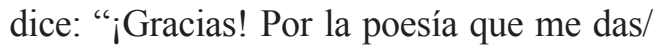
para poder hablar de Ti, Amor.” (161)

En el siguiente poema -“¿Mi poesía?”Helena Ospina nos define qué es en realidad su quehacer poético. Aquí, en esta especificación, la autora parece decirnos 
que no importa lo que la crítica literaria pueda decir, ya que es solamente: "Vida vivida, vida agradecida, / vida recibida, vida amada por ser Tú quien así me la das, / me la haces ver, querer ofrecer." (161). Y con estos versos se comprueba la asunción anterior: la poesía es divina y como tal vuelve a su Creador; es por lo tanto un acto de Amor y, para Helena Ospina específicamente, comunicación de su alma con su Creador.

Una de las características de este poemario es la de su gran extensión, consta de 315 poemas. Aquí en esta Canción séptima encontramos la razón de ese número. La poeta nos dice que cada poema es una gota de Amor en la que le devuelve todo a su Bien. De nuevo se corrobora la idea del origen divino de la poesía y además su doble función. Por una parte, el oficio de la poesía - dada su divinidad- tiene como razón de ser volver a su Creador; pero por otra parte, sirve de pretexto para expresar el Amor: "Y... ¿mi poesía? ¡Garabatos! De ésa Tu vida/ vivida en mí ¡oh Amor! (161)

\section{Canción última}

La Canción última -que vendría a ser la octava- se distingue por 17 brevísimos cantos, con un predominio de estrofas de dos, tres y cuatro versos. La correspondencia entre forma y contenido, alma $y$ cuerpo se alcanza a plenitud, porque se da la unión tan ansiada donde sobran las palabras. En esta Canción el alma pide "no más, aquí, quedar”. (33) La comunión del alma con su Creador se ha consumado, y el alma desea abandonar su morada física, pues ella ya vibra con su Amado en otro espacio. En esta última Canción se expresa verdaderamente la tercera etapa del proceso místico. Helena Ospina nos define esta culminación. Véase el poemita "Diagnóstico": "Diagnóstico de muerte: ¡Amor!/ Diagnóstico de vida: ¡Amor!/ Muere: de ¡Amor!/ De no caber tanto amor en esta vida ¡Amor! (182) El alma en otras palabras encontró su Canción, y por eso: "ya no quiere en la tierra más quedar.” (185)

\section{Simbología}

Uno de los misterios de vida y de acción en la mística de Helena Ospina descansa en el uso del número tres. Su uso no es un hecho a la ligera, sino que alcanza dimensión simbólica, y es posible explicar - en esta representación numérica- su búsqueda del Amor divino. En este poemario, el pequeño canto "Mis tres gracias" - poema ya citado y que pertenece a la Canción VIalude al proceso de arrebatamiento sufrido por la poeta a causa del Amor divino: "Cautivaste mi alma primero por la Belleza, / viniste luego a unirle a tu Verdad, / impulsaste mi voluntad a tu Bien/ y ahora estas tres Gracias no se separan de Ti jamás." (152) Belleza, Verdad y Bien son las amarras que la sujetan al Amor.

El alma no sólo está atada a las tres Gracias anteriores, sino a cualidades implícitas, regalos que el amado imprime en el alma escogida. Veamos "Acróstico"s de la Canción VII: “¡Humilde! / ¡Obediente! / ¡Fiel! / Y ¡qué batalla libraré! Si me atas Tú, ¡a los tres!” (162)

5 Acróstico: HOF (Helena Opina de Fonseca): Humilde, Obediente, Fiel. 


\section{Conclusión}

En conclusión, la vida y la poesía de Helena Ospina, siendo poesía igual a vida, se concreta en una tríada que tiene su centro en el Amor:

¿Mi vida? Circunscrita en ese espacio ilimitado de Tu Amor.

¿Mis circunstancias? Inscritas en ese radio de Tu Amor.

¿Mi apostolado? Clavado en ese tomo de Tu Amor. (183)

Las aseveraciones anteriores nos hablan de una resonancia profunda de San Juan de la Cruz en Helena Ospina, porque al igual que él, el sentido de su poesía, vida vivida, se descifra en un: "Todo por Dios, todo para Dios. " (Poesía española, 266)

Y en cuanto al proceso místico en Sonata de Otoño, se puede observar un "ir y venir" entre las etapas, una "acción zigzagueante del alma”, acción que es a la vez canto y gemido enamorado, y no podría ser de otra manera, ya que este proceso es una expresión auténtica del espíritu. Pero a pesar de eso, se puede vislumbrar que en la Canción primera el alma ya entra a esa segunda etapa del proceso místico. En la segunda y la tercera Canciones, el alma parece retroceder, pues todavía está en una etapa de purificación. La cuarta, quinta y sexta Canciones nos remiten, sin lugar a dudas, a la etapa intermedia. Y la séptima es la vislumbre gozosa del alma con su Creador, donde se cumple parte del Concierto universal. Y digo parte, pues la armonía completa se va logrando a medida que nosotros, todos, vayamos entonando también nuestra propia canción de Amor hacia el Amado.

\section{Bibliografía}

Alonso, Dámaso. Poesía española (5 ed.). Madrid: Editorial Gredos, 1966. Impreso.

Hatzfeld, Helmut. Estudios literarios sobre mística española ( $3^{\mathrm{a}}$ ed.). Madrid: Editorial Gredos, 1976. Impreso.

Ospina, Helena. Sonata de otoño. Canción consumada. San José: Promesa, 2007. Impreso. 